\title{
Abertura de mundo, natureza e finitude na preleção de 1929/30 de Heidegger
}

\author{
Openness of the world, nature and finitude in \\ Heidegger's 1929/30 lecture
}

\begin{abstract}
Resumo: Este artigo apresenta a abordagem realizada por Heidegger dos conceitos de mundo, natureza e finitude a partir da prelação de 1929/30, intitulada Os Conceitos Fundamentais da Metafísica: Mundo, Finitude e Solidão. Ao concentrar e manter grande parte da problemática da ontologia fundamental elaborada em Ser e Tempo, a preleção de 1929/30 constitui-se por ser um vértice no pensamento de Heidegger, equilibrando-se entre a ontologia fundamental e os livros e preleções que vieram depois dos anos de 1930. Deste modo, ao apresentar a transformação do conceito de abertura na preleção de 1929/30, torna-se possível argumentar que Heidegger elabora um conceito de finitude oriundo da relação do ser humano com a natureza, distinto do conceito de finitude existencial pensado a partir da relação do ser humano com a possibilidade da morte. Esse conceito de finitude assinala, por sua vez, a inserção não apenas da finitude existencial, mas também da finitude de ser. Palavras Chave: ontologia, mundo, finitude, natureza, Heidegger
\end{abstract}

\begin{abstract}
This article presents Heidegger's approach to the concepts of world, nature and finitude in the lecture curse of 1929/30, entitled The Fundamental Concepts of Metaphysics: World, Finitude and Solitude. By concentrating and maintaining a large part of the fundamental ontology problem elaborated in Being and Time, the lecture of 1929/30 constitutes itself as a vertex in Heidegger's thought, balancing between the fundamental ontology and the books and lectures that came after 1930s. Thus, when presenting the transformation of the concept of openness in the lecture of 1929/30, it becomes possible to argue that Heidegger elaborates a concept of finitude arising from the relationship of human beings with nature, distinct from the concept of finitude existential thought from the relation of the human being with the possibility of death. This concept of finitude marks, in turn, the insertion not only of existential finitude, but also of finitude of being.
\end{abstract}

Keywords: ontology, world, finitude, nature, Heidegger

\section{Introdução}

A preleção Os Conceitos Fundamentais da Metafísica: Mundo, Finitude e Solidão, escrita por Heidegger em 1929/30, não é nem tão somente uma continuação da ontologia fundamental, tampouco a elaboração de uma investigação que se propõe contra esse projeto. Essa preleção constitui-se por ser um vértice no pensamento de Heidegger, equilibrando-se entre a ontologia 
fundamental e os livros e preleções que vieram depois dos anos de $1930^{1}$, uma vez que estes se aproximam muito mais do que é considerado a virada. É de extrema importância fazer essa tentativa de localizar essa obra na cronologia do pensamento de Heidegger, sobretudo para saber, minimamente, quais são os conceitos básicos de Ser e Tempo que Heidegger preserva e opera na preleção de 1929/30, bem como saber no que consta a grande diferença.

De antemão, é possível dizer a preleção de 1929/30 conserva boa parte da temática da ontologia fundamental ${ }^{2}$, mantendo conceitos centrais como o da temporalidade ekstáticohorizontal, o conceito de cuidado, o ser-aí enquanto poder-ser que se singulariza pela decisão antecipatória, a discussão sobre os modos de ser e o conceito de verdade. A investigação dos problemas de 1929/30 parte de outra perspectiva, mas que de modo geral não se constitui como um rompimento nesse período da ontologia fundamental. Mas, então, qual é a diferença? Como tese interpretativa, penso que uma grande diferença entre as duas obras é o modo como Heidegger elabora o conceito de mundo a partir de uma nova compreensão do conceito de abertura.

Em 1929/30, Heidegger parece ter reconhecido que o fenômeno da natureza ficou extremamente problemático na ontologia fundamental. Neste sentido, a estrutura ser-no-mundo passa a ser modificada, levando Heidegger a uma nova abordagem a partir da qual há uma condição adicional para essa estrutura: o ser-no-mundo depende do acontecimento da formação de mundo. A formação de mundo é um evento que precede a existência individual, mas que continua a ocorrer. Contiguamente a isso, mudam-se algumas outras coisas, uma vez que na formação de mundo haverá a inserção dos conceitos de vigência, a normatividade da compreensão dos sentidos de ser a partir da retração dos mesmos, e o próprio conceito de natureza, que representa uma problemática por si mesma, cujo ápice ocorre no abismo entre existência e vida.

Deste modo, em um primeiro momento será apresentado o conceito de mundo a partir da perspectiva de que a existência humana é compreendida como ser-transposta para o interior da natureza vivente. Após isso, será possível apresentar o conceito de mundo como abertura do ente enquanto tal no todo, conjuntamente ao conceito de tédio. Por fim, serão apresentados os conceitos de formação de mundo, finitude e o existir humano na metafísica do abismo.

\footnotetext{
Um importante elemento não tratado aqui concerne ao modo como Heidegger elaborou seu pensamento durante a transição entre 1927 e 1930. Refiro-me especificamente aos trabalhos do Heidegger sobre metontologia e metafísica do Dasein. O problema do "ente no todo" ganha corpo nessas investigações, assim como a ênfase na noção de liberdade como vinculação, de modo que seria a liberdade que articularia a vinculação aos diversos modos de ser e, em consequência, a finitude e a verdade dos modos de ser. Algumas obras no qual esse desdobramento aparece são Os fundamentos metafísicos da lógica (Heidegger, 1984), Da essência da verdade (GA 34), A essência da liberdade humana (GA 31), e Kant e o Problema da Metafísica (GA 3).

2 Um importante exemplo dessa situação ocorre na seguinte passagem da preleção de 1929/30: “Todos os conceitos filosóficos são indicações formais (...) o que se tem em vista com este caráter fundamental dos conceitos filosóficos, em contraposição aos conceitos científicos em geral, pode ser explicitado através de um exemplo particularmente opressor - o problema da morte e, em verdade, da morte humana. Em Ser e Tempo §46, desenvolvi esse problema da morte em um contexto totalmente determinado. Este contexto pode agora ser deixado de lado. (...) o ser-aí do homem é um ser para a morte. O homem sempre se relaciona de alguma maneira com a morte, isto é, com a sua morte. (...) Compreender o ser-aí significa: compreender-se por sobre o ser-aí, poder ser-aí. Compreender-se a partir desta possibilidade mais extrema do ser-aí diz: agir no sentido de ser-colocado nesta possibilidade mais extrema. Marcado por um movimento antecipativo, este ser-livre para a própria morte foi caracterizado como o modo do ser-próprio autêntico do ser-aí, como a autenticidade da existência em contraposição à inautenticidade das perambulações cotidianas esquecidas de si. Mesmo se arrancarmos o problema de seu contexto e só mantivermos diante de nossos olhos seu conteúdo particular o modo como ele é exposto, não deve ser muito difícil conceber o decisivo” (Heidegger, 2006, p. 336-337/GA 29/30, p. 425-426, grifo do autor).
} 


\section{Mundo e natureza na ontologia heideggeriana}

Há muitas críticas sobre a ausência da abordagem do conceito de natureza em seus diversos aspectos na ontologia fundamental presente em Ser e Tempo. O problema central é compreender como Heidegger lidou com a dificuldade de apresentar um sentido do natural em que este não fosse derivado de outros âmbitos, sejam prático-operativos, sejam teóricos. O âmbito do natural aparece mediado por outros modos de ser e acaba por encobrir o sentido originário da natureza, de modo que o encontro cotidiano com o natural se mostre como não originário. É neste sentido que uma característica central no fenômeno da natureza é a sua retração, colocada em evidência pelo modo de ser da vida ${ }^{3}$. O sentido originário de natureza compreendido a partir da retração escapa às reduções dos comportamentos produtivos e temáticos que se teria com a natureza.

No caso do sentido de ser da vida, ela é entendida como algo que se caracteriza por uma retração na intencionalidade humana. Ao elaborar as bases hermenêuticas para uma interpretação da vida e da natureza, em Ser e Tempo o modo de ser da vida foi interpretado a partir da interpretação privativa, que teve por objetivo justamente apreender a vida nesse movimento de retração e de privação nos pressupostos das ciências positivas, uma vez que em toda objetivação conceitual da vida já atuariam pressupostos ontológicos que a encobririam em seu sentido originário. Neste sentido, a interpretação privativa permite compreender a vida a partir de seu ocultamento, em seu ausentar-se. Em todo comportamento com entes vivos há um compartilhamento parcial, de modo que a vida sempre se dá nesse contexto de retração.

O passo seguinte de Heidegger deu-se na preleção Os Conceitos Fundamentais da Metafísica, uma vez que nessa obra se realizou de fato a interpretação sobre o natural e tomou o sentido de ser da vida como tema. O conceito de natureza, presente nos CFM, parte da premissa de que a vida dos organismos vivos transcorre em um círculo ambiental dentro de uma totalidade estrutural chamada de perturbação. A discussão de fundo dessa obra é o conceito de mundo, de modo que as teses comparativas tratadas por Heidegger - "o animal é pobre de mundo”, “o homem é formador de mundo”, “a pedra é sem mundo” - são investigadas a partir do fenômeno do mundo ${ }^{4}$.

Neste sentido, ao comparar existência e vida, Heidegger opera com a distinção entre dois âmbitos ontológicos distintos. O problema ocorre quando se busca compreender o modo como o ser-aí humano compreende e se comporta com a natureza, pois a natureza de modo geral se caracteriza por mostrar-se de modo incompleto à existência. Essa recusa foi entendida em um primeiro momento como a pobreza de mundo do animal. No entanto, com o desdobramento da análise, Heidegger compreendeu que a tese sobre a pobreza de mundo depende da análise sobre o organismo ser estruturado pela perturbação. Esse conceito designa a abertura animal como uma absorção pulsional, de modo que o organismo é absorvido em um círculo ambiental que o impede de compreender os entes enquanto entes. Mas, mais do que isso, podemos compreender que o que está presente nessa análise é que o ser-aí humano é transposto para esses círculos ambientais dos viventes, de modo que a formação de mundo ocorre na transcendência pra modos de ser que não se mostram por completo.

Calarco (2005, e 2008) faz uma interessante reflexão sobre a questão do animal, e diz que essa problemática precisa se confrontar com a ontologia proposta por Heidegger, dada à centralidade e a abertura no campo de investigação que essa interpretação proporcionou. Contudo, a leitura de Calarco é crítica, de modo que ele dirá que Heidegger ainda se mantém comprometido com algum tipo de antropocentrismo metafísico, pois de acordo com essa leitura Heidegger estaria falando de um abismo entre a essência do ser humano e a essência do animal. Elden (2006) também faz um comentário interessante sobre esse aspecto, a focar mais na distinção entre homem e animal a partir do conceito de logos. Também Cf. Aho (2009).

4 Na discussão sobre essas teses, a primeira distinção importante feita por Heidegger concerne à distinção entre órgão e utensílio, além da discussão sobre uma abordagem científica da natureza. Essa discussão foi apresentada em Silveira (2014). Também cf. Torres (2010). 
Ao deixar a abordagem transcendental para uma abordagem histórico-metafísica do conceito de mundo, torna-se mais claro o problema da normatividade, quando considerada a retração dos sentidos de ser. O acontecimento transformativo da formação de mundo é algo que ocorre e continua a ocorrer. Esse acontecimento, por sua vez, é aquilo que permite o ser humano vir a ser, no deixar viger o mundo a partir do projeto que possibilita possibilidades. Uma das consequências desse possibilitar, do projeto na formação de mundo, é que toda vinculação aos entes passa a ser histórica e finita, uma vez que o mundo é entendido como uma emergência, sem o qual o ser humano não vem a ser. Neste sentido, é preciso admitir que a força normativa para a vinculação aos sentidos de ser advém da negatividade do próprio ser, não apenas da negatividade da existência humana.

\subsection{O acontecimento da abertura}

Em Ser e Tempo, Heidegger apresenta o ser-aí humano como possibilidade existencial, e isso significa dizer que o ser-aí é um poder-ser que projeta-se e mantém-se em determinada possibilidade, estruturadas temporalmente. O caráter ekstático-horizontal da temporalidade finita mostra a existência humana como desveladora e descobridora, justamente porque o ser-aí é caracterizado por transcender. Ademais, o elemento da intencionalidade caracteriza a existência humana como "ser se comportando junto ao ente" (Heidegger, 2012, p. 231/GA 24, p. 224). Neste sentido, a transcendência para modos de ser possibilitada pela estrutura ekstáticohorizontal da temporalidade originária permite ao ser-aí compreender o ser dos entes. Nessa compreensão, o comportamento intencional do ser-aí para com os entes descobertos no horizonte esktático é aberto. Tendo em vista que o ser-aí humano é determinado pela temporalidade originária como um originário "fora de si”, o ser-aí transcende para os sentidos de ser já de modo histórico e, o transcendente para qual a existência transcende é o mundo.

Com o conceito de transposição, apresentado na prelação de 1929/30, é possível ver a partir de outra perspectiva a transcendência do ser-aí humano para modos de ser de outros entes. Na preleção de 1929/30, os âmbitos de entes investigados por Heidegger foram a vida, pedra e existência humana. A investigação de Heidegger mediante a articulação das três teses diretrizes revelou que ao mundo pertence à abertura do ente enquanto ente (Heidegger, 2006, p. 314/GA 29/30, p. 397).

Não obstante o conceito de mundo ainda não ter sido compreendido em todos os seus aspectos, neste ponto da investigação o objetivo de Heidegger foi mostrar que o ente é manifesto onde quer que o mundo se dê (Heidegger, 2006, p. 315/GA 29/30, p. 398). O problema é que mundo é um acontecimento, a partir do qual uma variedade de entes com distintas individuações ontológicas podem ser desvelados. Neste sentido, na abertura de mundo o ser-aí humano já está obrigatoriamente em uma vinculação com esses entes, mesmo que eles se mostrem a partir de uma retração. Heidegger ressalta ainda que, concernente à discussão sobre a tese da animalidade, o que ela tornou visível foi justamente uma multiplicidade de entes aberta para o existente humano:

A questão é que justamente a discussão sobre a animalidade mostrou que uma multiplicidade de entes está aberta para nós: natureza material, natureza inanimada, natureza vivente, história, obra humana, cultura. Mas tudo isso não se encontra justaposto e entrelaçado enquanto uma multiplicidade, representado para nós homogeneamente em um palco mundial (Heidegger, 2006, p. 315/GA 29/30, p. 398).

As questões levantadas por Heidegger visam saber qual e como seria uma atitude fundamental do ser-aí humano em relação ao ente, uma vez que em meio a essa multiplicidade indistinta a relação do homem com o ente é sempre uma relação desenraizada. Deste modo, 
compreender que há relações fundamentais do ser-aí com o ente, relações que podem inclusive ser despertas a partir da cotidianidade. Outro ponto importante a se destacar é que por meio da interpretação da animalidade a compreensão de que há diversos modos de ser é intensificada (Heidegger, 2006, p. 317/GA 29/30, p. 400). Neste sentido, a investigação precedente ganha um novo elemento, tal como diz Heidegger:

A animalidade não é tomada em consideração agora com a pobreza de mundo enquanto tal, mas enquanto um âmbito do ente que está manifesto, e, com isto, exige de nós uma determinada relação fundamental com ele; relação na qual, contudo, não nos movemos inicialmente (Heidegger, 2006, p. 317/GA 29/30, p. 400, grifo do autor).

Tendo em vista que Heidegger está inquirindo o fenômeno do mundo, o modo como ele compreende a descrição do animal para articular o fenômeno do mundo se localiza no nível de "manifestabilidade" do animal enquanto tal (Colony, 2007, p. 12). Neste sentido, é preciso ver como Heidegger pensa a relação do existente humano para a animalidade a partir de uma nova abordagem do conceito de abertura, pois é esse conceito que possibilitará a pergunta pelo mundo.

Ao inquirir sobre como se dá a acessibilidade do ente e se acessibilidade do ente é a nota determinante no fenômeno do mundo, a questão em última instância versa como se dá a abertura do ente. Na medida em que o ponto de partida da pergunta pelo mundo é a pergunta sobre o acontecimento da abertura, o mundo é um acontecimento que antecede a existência humana e perfaz a historicidade.

Por conseguinte, Heidegger quer ressaltar que a pergunta sobre a formação de mundo, isto é, a pergunta que tem o homem como tema, justamente coloca em questão a respectiva existência do homem (Heidegger, 2006, p. 322/GA 29/30, p. 407). Em outros termos, é colocada em questão justamente a existência daquele que faz a questão. Contudo, para inquirir pela essência do homem Heidegger não leva em conta às disciplinas da antropologia e psicologia, tal como ele recorreu à biologia e a zoologia para investigar a noção de organismo. Heidegger prescindiu dessas disciplinas com a justificativa de que na primeira parte da preleção (de 29/30) foi analisado o despertar de uma disposição afetiva fundamental do ser-aí (Heidegger, 2006, p. 323/GA 29/30, p. 408).

\section{O tédio}

A fenomenologia dos humores investigada por Heidegger não visa à elaboração de um catálogo dos diferentes ânimos e daquilo que eles revelam. A investigação toma como central aquilo que Heidegger chama de humores fundamentais, justamente por estes humores serem os responsáveis por abrir o ser-aí humano de um modo singular. A despeito de Heidegger dizer que há outros humores fundamentais, sua análise recai quase que exclusivamente ao tédio e à angústia.

Em termos de abertura, a grande diferença entre esses dois humores é que a angústia, ao singularizar a existência, revela o nada, concernindo diretamente à finitude do ser-aí humano a partir da negatividade aí determinante. No caso do tédio, ele revela o ser-aí humano enquanto um ente que existe em meio ao ente na totalidade a partir de uma relação direta com a temporalidade. Essa distinção geral servirá para situar melhor a discussão sobre o fenômeno do tédio.

A discussão sobre o conceito de tédio está inserida um pouco após o início da preleção de 1929/30, e tem como objetivo apresentar uma disposição de humor que possa despertar o ser-aí humano para uma relação fundamental com os entes. No entanto, à diferença da angústia, de 
modo geral o tédio não será tomado como um humor raro ${ }^{5}$. Neste sentido, o que é o tédio? Heidegger diz o seguinte: "o tédio (die Langeweile) (...) indica de forma quase palpável uma relação com o tempo: um modo como nos colocamos diante do tempo, um sentimento de tempo" (Heidegger, 2006, p. 97/GA 29/30, p. 120). Não apenas com o tempo de modo geral, mas, literalmente, o tédio indica algo como um "longo enquanto". Estar entediado não diz respeito ao ser humano querer fazer algo e faltar-lhe disposição e, mediante esse querer, estar privado de uma possibilidade que supra essa vontade. Estar entediado concerne a um modo específico de impotência perante as possibilidades, de um não poder vincular-se nem às coisas, nem a si mesmo. Deste modo, Heidegger diz, de modo geral, que o entediante é: "modorrento, aborrecedor; o que não estimula nem excita, não nos oferece nada, não tem nada para nos dizer, não tem nada a ver conosco” (Heidegger, 2006, p. 101/GA 29/30, p. 126).

Para explicitar como ocorre o tédio, Heidegger parte dos comportamentos mais cotidianos para mostrar como ele se manifesta em sua dimensão mais superficial. Assim como em outras análises, Heidegger identifica no tédio três formas distintas. Antes de apresentar a primeira forma do tédio, Heidegger distingue entre o ser-entediado por algo, e o entediar-se com e junto a algo. A primeira forma do tédio concerne justamente ao ser entediado por algo. Essa situação caracteriza-se por ser um momento em que o existente humano encontra-se preso a uma situação específica $^{6}$. Ao estarmos presos a uma situação específica, o curso hesitante do tempo causa uma aflição, devido à demora do tempo em passar. Por conseguinte, essa situação é caracterizada por uma situação específica e sabemos qual é a essa situação; além disso, somos mantidos presos a ela, e não conseguimos preencher o vazio que fica à espreita. A partir disso, Heidegger apresenta os dois momentos estruturais do tédio, que são a serenidade vazia e a retenção. A retenção do tempo é o que determina a espera aflitiva, e buscamos distância da serenidade vazia do tédio através de um passatempo. Mediante a isso, Heidegger diz que nossa ação e lassidão são absorvidas por algo, uma vez que somos cativados pelas coisas (Heidegger, 2006, p. 122/GA 29/30,p. 153). Sobre a serenidade vazia, Heidegger diz o seguinte:

Elas [as coisas] nos abandonam a nós mesmos. Porque elas não têm nada a oferecer, elas nos deixam vazios. Deixar vazio significa não oferecer nada enquanto algo simplesmente dado. Serenidade vazia diz: não receber nenhuma oferta do que está simplesmente dado (Heidegger, 2006, p. 124/GA 29/30, p. 155).

Já a segunda forma do tédio, o entediar-se junto a algo, consiste em ser muito mais sutil. No entanto, a sua abrangência é muito mais ampla. Enquanto na primeira forma do tédio o passatempo foi entendido como um comportamento que visava estimular o tempo a passar mais rápido, dada aflição causada pelo tempo estagnado, na segunda forma do tédio, por outro lado, todo o comportamento que se teria na situação é visto como sendo o passatempo. Esse tédio aparentemente é mais suave do que a primeira forma, uma vez que a sensação de um longo enquanto permanece sob controle, embora permaneça a compreensão de que há algo indeterminado que entedia. No entanto, diz Heidegger, esse "eu não sei o quê" que entedia mostra-se mais potente do que a primeira a forma. Essa situação pode ser vista quando é contraposto a isso o passatempo, agora nessa segunda forma do tédio. Cada comportamento isolado é entendido como passatempo, desde o mexer dos dedos ao fumar um cigarro.

Na primeira forma do tédio ${ }^{7}$, a serenidade vazia é vista em função de uma ausência do preenchimento, pois aquilo que se buscava preencher com alguma ocupação recusa-se a nós (Heidegger, 2006, p. 143). Na segunda forma do tédio, cuja característica é a de um entediante

\footnotetext{
5 Heidegger também apresenta essa discussão no interessante ensaio Que é metafísica? (1973).

6 Heidegger exemplifica do seguinte modo: quando alguém precisa esperar por quatro horas um trem, em uma estação vazia perdida em algum lugar um tanto inóspito, e não há passatempo que impeça a hesitação do tempo. Heidegger (2006, p. 155-156/GA 29/30, p. 196-197) faz um quadro comparativo de todos os momentos estruturais das duas primeiras formas do tédio.
} 
indeterminado, o que ocorre não é a ausência de preenchimento de um vazio previamente dado, mas antes a formação de um vazio. Heidegger sintetiza assim essa segunda forma do tédio:

\begin{abstract}
O tempo que tomamos para nós, dizemos, é o nosso tempo. O tempo estagnado é o nosso passado essencial obstaculizado e o nosso futuro desarticulado: ou seja, o tempo de toda a nossa existência em uma transformação peculiar. (...) Este tempo estagnado é o que nós mesmos somos: o nosso si-próprio como o que é deixado para trás em relação à sua proveniência e ao seu futuro.(...) Este agora estagnado nos impõe a vinculação com ele. O tempo estagnado não apenas não nos abandona, mas justamente nos cita, ele nos posiciona. Ao sermos assim posicionados, ao sermos deixados soltos em meio à participação na situação pelo agora estagnado, que é o nosso si-próprio mesmo, apenas abdicado e vazio, nos entediamos (Heidegger, 2006, p. 150/GA 29/30, p. 189).
\end{abstract}

Por fim, na terceira forma do tédio, chamada de tédio profundo, o ser-aí humano é entregue ao ente na totalidade que se recusa. Nessa terceira forma do tédio não está em jogo nem o serentediado por, nem o entediar-se junto a..., mas o "é entediante para alguém”, além de não ser pertinente nenhuma forma de passatempo. Heidegger define do seguinte modo o tédio profundo:

O tédio é o banimento do horizonte temporal; este banimento faz com que seja eclipsado o instante pertinente à temporalidade, para impelir, em um tal eclipse, o ser-aí banido para o interior do instante como o elemento propriamente possibilitador de sua existência; e esta existência só é possível em meio ao ente na totalidade, que se recusa no horizonte do banimento justamente na totalidade (Heidegger, 2006, 180-181/GA 29/30, p. 230, grifo do autor).

Com essa formulação, Heidegger pretende apresentar uma forma de tédio que atinge a raiz existencial humana, uma vez que o ser-aí é banido do ente na totalidade pelo próprio tempo. O ente na totalidade torna-se indiferente, vazio. No entanto, à diferença da angústia, o tédio profundo não revela o nada ${ }^{8}$.

No tédio profundo, o vazio ocorre pela recusa do ente na totalidade, e a serenidade vazia em um ser-entregue a essa recusa. Algo importante nesse ponto é como a existência humana é remetida a esse vazio, pois o ser-aí humano, por ser em meio ao ente e comportar-se em meio ao ente, comporta-se também com esse vazio ocorrido pela recusa do ente na totalidade. Heidegger diz o seguinte:

O tédio e a serenidade vazia consistem aqui na entrega ao ente, que se recusa na totalidade. O que traduz o fato de o ente na totalidade recusar as possibilidades de ação e inação para um ser-aí em meio a ele? Toda recusa traz em si mesma uma indicação do que é negado: isto é, um tornar manifesto. O que indica neste recusar-se do ente que no todo se recusa? Em relação ao que de algum modo poderia ou deveria ser dado ao ser-aí? Justamente as possibilidades de sua ação e inação. Em relação a estas possibilidades do ser-aí, o ente na totalidade expressa a recusa. A recusa não fala sobre isto, não abre quanto a isto nenhuma discussão, mas, recusando, aponta para estas possibilidades e as expressa, à medida que as recusa. (...) $\mathrm{O}$ ente na totalidade tornou-se indiferente. (...) $\mathrm{Na}$ recusa reside uma referência a um outro. Esta referência é o anúncio das possibilidades que se encontram a esmo (Heidegger, 2006, p. 167/GA 29/30, p. 212).

A recusa do ente na totalidade nessa forma do “é entediante para alguém” é ocasionada pela própria temporalidade originária, que enquanto horizonte temporal bane o ser-aí que, por sua vez, não encontra o caminho até o ente (Heidegger, 2006, p. 174/GA 29/30, p. 221). O horizonte pleno do tempo - passado essencial, presente (instante) e futuro (advir a si) - é a condição para que o ente se recuse em sua quididade, modalidade e totalidade (Heidegger, 2006, p. 172/GA 29/30, p. 218). No entanto, como é possível sair desse aprisionamento? Através da própria temporalidade, pois Heidegger afirma também que ao ser tocado pela recusa do ente na totalidade, o que ocorre é a possibilitação da ação. A decisão tem o poder de romper o serbanido pelo tempo. Neste sentido, a força normativa desse conceito de finitude - distinto do

8 Sobre o nada e a negação, cf. Reis (2008). 
conceito de finitude existencial, cuja compreensão se dá a partir da relação do ser-aí humano com a possibilidade da morte - advém de uma recusa, não do nada, mas do ente na totalidade.

\title{
3. O homem existe em meio ao ente
}

A recusa do ente na totalidade não é simplesmente algo que impede a relação do ser-aí humano para com os entes, mas ao contrário: na recusa há uma referência ao ente. É neste sentido que o problema da natureza e o modo de ser da vida tornam-se insignes, uma vez que a manifestação deles na abertura de mundo mostra-se sempre a partir de uma retração. Se é preciso admitir que há um sentido de ser que não é constituído em sua plena positividade pela temporalidade originária, incorporando uma negatividade intrínseca ao seu ser, a força normativa para a compreensão de todos os sentidos de ser pode ser melhor compreendida. É precisamente esse ponto em que se encontra também o conceito de finitude advindo não da relação da existência com a morte, mas da existência com a natureza. Esse conceito de finitude é mais amplo, pois incorpora uma conexão entre natureza e história distinta daquela presente em Ser e Tempo. Esse conceito de finitude provém da finitude de ser. Quando Heidegger investiga o tédio profundo, ele diz o seguinte:

\begin{abstract}
O ente recusa-se na totalidade. Ele recua para o interior de uma indiferença. Tudo vale tanto e tão pouco. O ente retrai-se para nós, mas continua de qualquer modo como o ente que é. Todo ente retraise para nós em todo e qualquer aspecto: para tudo o que lançamos o olhar e como quer que lancemos; em toda e qualquer consideração: todo ente para o qual voltamos o olhar enquanto um ente que foi, que se tornou e passou, como quer que voltemos para lá o olhar; todo ente em toda e qualquer intenção: todo ente que vislumbramos como algo por vir e como quer que o vislumbramos (Heidegger, 2006, p. 172/GA 29/30, p. 218).
\end{abstract}

A partir da discussão sobre o tédio, os ser humano foi compreendido como um ente que existe em meio ao ente na totalidade, mas que se recusa. Além disso, a partir das três teses diretrizes, Heidegger mostrou que o existente humano é um ser transposto para o interior do círculo envoltório do animal, para o vivente em geral, para os seres inanimados e para outra existência humana (Heidegger, 2006, p. 317/GA 29/30, p. 401). O animal, por sua vez, foi caracterizado por possuir como estrutura fundamental a perturbação. No todo da perturbação, o animal possui um círculo de desinibição, enquanto sua estrutura relacional (Buchanan, 2008, p. 93). No entanto, dado o nivelamento dos modos de ser na cotidianidade do ser-aí, a natureza viva e não-viva aparece como uma homogeneidade indeterminada, de tal modo que tudo fica indiferente. Por outro lado, se o ser-aí humano formador de mundo transcende para possibilidades, compreendendo assim os modos de ser, a transposição para o modo de ser da vida significa transpor-se para o espaço de comportamento possível do animal, isto é, o seu círculo de desinibição no todo da perturbação: "o ser-aí humano experimenta em si uma peculiar transposição para o interior do contexto do círculo envoltório próprio ao vivente” (Heidegger, 2006, p. 319/GA 29/30, p. 403, grifo do autor).

Se os círculos envoltórios dos animais constituem-se como o espaço de comportamento possível dos mesmos, então eles não são apenas justapostos uns aos outros, como se fossem uma estrutura fixa e sem distinção. Além de esse não ser o caso, Heidegger ressalta que cada animal e cada espécie conquistam para si de maneira própria o círculo de desinibição (Heidegger, 2006, p. 317/GA 29/30, p. 401). A dinâmica dos círculos envoltórios é própria e mostra-se como uma inserção de um círculo envoltório no outro. Neste sentido, o círculo envoltório de um gato é diferente do círculo envoltório de uma abelha e, por sua vez, o da abelha é diferente do círculo envoltório de uma coruja. É neste sentido que cada animal e cada espécie animal possuem círculos envoltórios que lhes são próprios e que se sobrepõem uns nos outros. A essa multiplicidade com que se apresenta a animalidade em seus círculos envoltórios, abertos 
a partir da perturbação, Heidegger diz que ela é de uma riqueza descomunal, uma riqueza a que cotidianamente não é compreendida como tal (Heidegger, 2006, p. 317-318/GA 29/30, p. 401).

Pelo fato de o ser-aí humano compreender o todo da natureza de um modo homogênio e indistinto, Heidegger diz que o homem compreende os animais e as relações entre eles como uma relação de adaptação (Heidegger, 2006, p. 318/GA 29/30, p. 402). A crítica de Heidegger à doutrina da evolução se dá por esta repousar em uma pressuposição ontológica impossível. Segundo ele, a doutrina da evolução pressupõe que o ente subsistente é dado para os animais e é dado homogeneamente, de tal modo que aos animais restaria apenas adaptar-se (Heidegger, 2006, p. 318/GA 29/30, p. 402). A breve crítica feita por Heidegger consiste em mostrar principalmente que nem o ente é dado de modo subsistente para os animais e que nem os animais são dados de modo subsistente para o existente humano.

Do mesmo modo que os círculos envoltórios dos animais sobrepõem-se entre si em uma dinâmica de luta específica, há também um modo específico do existente humano se transpor para os círculos envoltórios dos animais (McNeill, 1999, p. 232). Não obstante Heidegger admitir que haja uma investigação biológica que justamente reconhece a autonomia do vivo de modo não redutível, esse modo não pode ser aquele advindo da cotidianidade, cuja relação com o natural é inadequadamente concebida como um muro que estivesse presente ao se tornar tema de uma investigação teórico-científica (Heidegger, 2006, p. 319/GA 29/30, p. 403). Tendo isso em vista, essa peculiar transposição do ser-aí humano para a natureza revela uma característica muito expressiva da existência, na qual o existente humano é em meio ao ente, tal como diz Heidegger:

\footnotetext{
Nós dizemos por isto: o homem existe de uma forma específica em meio ao ente. Em meio ao ente significa: a natureza vivente mantém-nos presos enquanto homens de uma forma totalmente específica. Não em função de uma impressão ou influência particulares, que a natureza vivente exerceria sobre nós, mas em função de nossa essência, quer experimentemos ou não esta essência mesmo em uma relação originária (Heidegger, 2006, p. 319/GA 29/30, p. 404, grifo do autor).
}

A importância dessa passagem concerne ao fato de Heidegger reconhecer que há uma relação fundamental da existência humana com a natureza e com os viventes de modo geral, de modo que o homem fique cativo e preso de uma forma específica. Essa relação fundamental torna-se visível com a disposição afetiva do tédio, pois é ela quem mostra o ser-aí como existindo em meio ao ente no todo. O ente no todo é uma característica do mundo entendido como abertura do ente enquanto tal.

\section{A formação de mundo e a abertura do ente enquanto tal no todo}

A discussão pela via comparativa das três teses diretrizes permitiu esboçar o conceito de mundo enquanto um acontecimento que precede o existente humano. Essa precedência do mundo que possibilita a existência humana é também uma precedência histórica (McNeill, 2006, p. 40). Ademais, a discussão com as outras regiões de entes circundou o aspecto do respectivo acesso desses entes a algo - se há e como há. Com o desenvolvimento da discussão, Heidegger mostrou que compreender o conceito de mundo apenas como acessibilidade não é suficiente. Isso ocorre porque, não obstante os animais também possuírem uma relação a algo, essa relação é caracterizada por uma privação nesse acesso. É neste sentido que mundo foi compreendido, ainda não de modo completo, como acessibilidade do ente enquanto tal. $\mathrm{O}$ último aspecto da discussão sobre o conceito de mundo se deu através da constatação de que o ser-aí humano existe em meio ao ente. Essa constatação teve como consequência o fato de que o existente humano, ao transpor-se para uma multiplicidade de entes, transpõe-se para a natureza vivente de um modo peculiar, tendo em vista o círculo de desinibição que caracteriza a natureza 
viva. O elemento adicional é o seguinte: aquilo que permite ao existente humano comportar-se com o todo é a disposição afetiva. Neste sentido, Heidegger diz o seguinte: "o ser-transposto para o interior da abertura a cada vez específica do ente na totalidade; e isto diz: para o interior da abertura do ser-aí enquanto tal, assim como ele se encontra disposto a cada vez em meio a essa totalidade” (Heidegger, 2006, p. 325/GA 29/30, p. 410). A partir desses elementos, os aspectos investigados por Heidegger para compreender o fenômeno do mundo são o enquanto e o no todo, uma vez que mundo é abertura do ente enquanto tal no todo.

\subsection{0 "enquanto tal” e o "no todo"}

O desenvolvimento do problema do mundo, cuja definição é abertura do ente enquanto tal no todo, revelou que é preciso explicitar dois momentos cruciais concernentes ao fenômeno do mundo, a saber: o momento do “enquanto" e o momento "no todo” (Heidegger, 2006, p. 332/GA 29/30, p. 420). O primeiro desses aspectos, o enquanto tal, é analisado por Heidegger conjuntamente a uma investigação concernente ao logos apofântico em Aristóteles ${ }^{9}$. Não obstante o modo de análise ser muito semelhante a outras de suas análises presentes em outras obras, a apresentação realizada por Heidegger na preleção de 1929/30 é extramente rica e detalhada. A característica que aí se assemelha concerne ao conceito de verdade, que é compreendido por Heidegger, em boa parte de suas obras até os anos 1930, pela dinâmica entre um discurso subterrâneo e condicionante da experiência não reflexiva, entendido como o enquanto hermenêutico, em contraposição ao comportamento reflexivo e que tematiza, entendido como o enquanto apofântico e que pressupõe a dimensão mais básica de abertura.

Na interpretação de Heidegger, na compreensão de um ente enquanto tal está implicada a ligação de um elemento a outro, ligação essa que é determinada pelo elemento do "enquanto". A referência aí em questão significa que ao se compreender algo enquanto alto, há uma ligação de algo que está no “enquanto” e para algo diverso dele (Heidegger, 2006, p. 330/GA 29/30, p. 417). O ponto central é que a proposição enunciativa pressupõe a estrutura-“enquanto”, uma vez que somente é possível discorrer sobre um ente a partir do momento em que já há uma abertura desse ente. Na análise de 1929/30 o logos é apresentado em ligação com o nous, este entendido como a “apreensão” significativa de algo. Por conseguinte, o modo de ligação possibilitado pela abertura que o homem tem para com o ente, determinado pelo nous e pelas diversas articulações do logos, é denominado como assumir uma atitude, em contraposição ao comportamento pulsional dos animais com os entes.

O aspecto da totalidade, da abertura do ente no todo, é visto a partir das disposições afetivas. A possibilidade de a existência humana orientar-se no mundo, descobrir os entes em particular, e a possibilidade de um saber de si mesmo acerca de como se está situado no mundo, ocorre a partir de uma abertura afetiva. Além disso, todas essas características possuem um elemento central que é a de uma abertura ao todo. Essa abertura ao todo é o que possibilita a vinculação fáctica da existência humana com qualquer ente e sentido de ser, inclusive com a natureza. É neste sentido que a totalidade, do ente no todo, é muito mais a forma com a qual a abertura do ente enquanto tal acontece. É justamente esse o sentido de correlação entre a estrutura“enquanto" e o "no todo".

Em ST, a estrutura ser-no-mundo determina o ser-aí enquanto um ente aberto aos distintos sentidos ou modos de ser, estruturados temporalmente no acontecer da historicidade do ser-aí. A seguinte passagem explica muito bem o conceito de ser-no-mundo:

De sua liberdade depende, ainda que dentro dos limites da condição de lançado, tão somente o que o Dasein descobre e a cada vez, e a direção, amplitude e modo desse descobrimento e abertura. (...) A

9 Cf. Silveira (2015).

Studia Heideggeriana, Vol. VIII, 2019 
redução do ser-no-mundo à unidade ekstático-horizontal da temporalidade torna compreensível a possibilidade ontológico-existencial dessa constituição fundamental do Dasein (Heidegger, 2009, p. 380/ GA, 2, p. 484-485, grifo do autor).

O conceito transcendental de ser-no-mundo presente em ST tem o pressuposto de que a abertura estruturada pela temporalidade originária possibilita a transcendência do ser-aí para o mundo. Neste sentido, em existir, o ser-aí é ser-no-mundo. Uma decisão livre possibilita, no máximo - o que não é pouco -, o ser-aí cindir-se da inautenticidade e decidir-se pela autenticidade. Isso ocorre porque o elemento do novo na ontologia fundamental é restrito, tendo em vista que o máximo de abertura para o novo advém da niilidade da temporalidade finita, que singulariza a existência. A mudança dessa concepção para o CFM é grande, pois na preleção de 1929/30 o conceito de acontecimento terá uma centralidade segundo a qual a temporalidade histórica daria uma amplitude maior à própria noção de abertura. Tendo em vista o necessário envolvimento com os entes, Heidegger explicitamente insere na noção de abertura a vinculação da existência humana com entes que escapam à compreensão projetiva. Na transcendência para um modo de ser que não se mostra por completo, a transcendência ocorre para o completo outro. Isso não apenas requer do ser humano uma atitude, como é um dos fundamentos para a formação da historicidade da existência.

Neste sentido, o nexo entre o “enquanto" e o “no todo” é estrutural. Uma vez que esse nexo é o que possibilita a acessibilidade do ser-aí ao ente enquanto tal e na totalidade. Neste momento encontra-se toda a problemática da preleção de 1929/30, pois o mundo enquanto formação de mundo será o abrir-se projetivo para a diferença ontológica.

\subsection{Formação de mundo}

Tendo em vista o que Heidegger pensa por totalidade, isto é, não o todo do ente no sentido da mensuração quantitativa ou mesmo qualitativa de todos os entes, a manifestação dos entes para o existente humano possui uma forma. A formação de mundo significa, em última instância, a abertura do ser-aí para os entes enquanto tais e no todo. Concernente a isso, Heidegger caracteriza triplamente o elemento “formar”, da expressão “formação de mundo", a saber: 1) ele o instala; 2) ele fornece uma imagem, um aspecto do mundo, ele o apresenta; 3 ) ele o perfaz, ele é o que enquadra e envolve (Heidegger, 2006, p. 327/GA 29/30, p. 414). Neste sentido, tendo em vista a insuficiência de uma abordagem apofântica para compreender o fenômeno do mundo, Heidegger mostra que a abertura pré-apofântica é justamente esse acontecimento da formação de mundo. Concernente à conexão entre esse acontecimento fundamental e à dimensão apofântica, Heidegger apresenta o fenômeno do mundo como uma relação unificada entre três momentos: 1 . o manter-se ao encontro da obrigatoriedade; 2. A integração; 3. O desentranhamento do ser do ente (Heidegger, 2006, p. 399/GA 29/30, p. 506).

O primeiro desses momentos concerne ao modo como o ser-aí se vincula aos entes, mesmo na recusa do ente na totalidade. Em contraposição ao comportamento pulsional do animal, no todo da perturbação, Heidegger mostrou que o existente humano assume uma atitude em relação ao ente. $\mathrm{O}$ logos foi definido como um poder velar ou um poder desvelar o ente a partir de uma abertura prévia. No entanto, tendo em vista que o logos pressupõe o estar aberto pré-apofântico para o ente, a vinculação aos entes é regulada pelos sentidos de ser que possibilitam o ser-aí assumir uma atitude para com os entes. Além disso, na medida em que a abertura pré-apofântica é o acontecimento da formação de mundo, essa vinculação não é determinada originariamente pelo logos. É deste modo que na formação de mundo sempre há um vínculo determinado para com os entes. Esse vínculo determinado que caracteriza o assumir uma atitude por parte do existente humano é dominado pela obrigatoriedade, de tal modo que seja possível uma desvinculação do ente, ainda que haja uma necessidade de ligação com os entes (Heidegger, 
2006, p. 414/GA 29/30, p. 525). Ademais, de acordo com Heidegger, esse manter-se ao encontro da obrigatoriedade só é possível para um ser livre (Heidegger, 2006, p. 388/GA 29/30, p.492).

O segundo momento concerne à característica já apresentada da totalidade. Todo assumir uma atitude do ser-aí para os entes só é possível a partir de uma totalidade já aberta. Neste sentido, é preciso a formação prévia de um todo para que um ente enquanto tal, isto é, em seu ser, possa assim ser compreendido (McNeill, 1999, p. 234). Dessa forma, para que se possa compreender um ente particular enquanto tal é preciso que esse mesmo ente já seja visualizado em uma originária relação para outros entes, para que ele possa ser compreendido enquanto ser este ente e não outro (McNeill, 1999, p. 234). Neste sentido, o "no todo” tem o sentido de relacionalidade. O momento da integração mostra que na formação de mundo sempre há a integração de entes em totalidades, sempre a partir de uma totalidade já vigente, tal como diz Heidegger: “o estar-aberto pré-lógico para o ente, a partir do qual todo e qualquer logos já precisa falar, sempre integra desde o princípio o ente a um “no todo”” (Heidegger, 2006, p. 398399/GA 29/30, p. 505, grifo do autor).

Os momentos da obrigatoriedade e o da integração são vistos em sua unidade através do terceiro momento, entendido como o desvelamento de ser (Heidegger, 2006, p. 414/GA 29/30, p. 525). Tal como mostra a abertura pré-apofântica para os entes, eles mesmos são integrados em totalidades e em vinculações obrigatórias. Neste sentido, tendo em vista que o estar aberto para o ente é o que possibilita o expressar-se sobre o ente, sobre a verdade ou falsidade, sobre eles existirem ou não e sobre os seus diversos modos, nesse estar aberto o ser do ente já precisa estar desvelado (Heidegger, 2006, p. 399/GA 29/30, p. 506). Por conseguinte, na integração dos entes já está desentranhado o ser dos entes.

A partir desses três momentos, é possível ver que todos os sentidos de ser que regulam a atitude do ser humano com os entes dependem da formação de mundo. Desta feita, Heidegger diz que o caráter unificado do acontecimento fundamental da formação de mundo, conduzido por esses três momentos, é o projeto (Heidegger, 2006, p. 414-415/GA 29/30, p. 527). O projeto possibilita possibilidades, pois ele é entendido justamente como a estrutura originária do acontecimento da formação de mundo que, tal como foi visto, condiciona a abertura prévia da existência. Neste sentido, projeto enquanto a unificação daqueles três momentos é projeto de mundo, de modo que mundo passa a ser entendido como a vigência de mundo, tal como diz Heidegger:

O que mostramos anteriormente como caracteres singulares desentranha-se, agora, como entrelaçado originariamente e de maneira una na unidade da estrutura primordial que é o projeto. Nele, acontece o fato de deixar-viger o ser do ente no todo do que perfaz seu caráter obrigatório a cada vez possível. No projeto vige o mundo (Heidegger, 2006, p. 418/GA 29/30, p. 530, grifo do autor).

Além disso, na medida em que o projeto é a estrutura originária da formação de mundo e a este acontecimento são pertinentes aqueles três momentos, no projeto é que se desvela o ser do ente. Dessa forma, o projetar é o próprio acontecimento da diferença ontológica, de tal modo que o projeto consiste na irrupção neste “entre”, tendo como momento estrutural desse acontecimento o “enquanto” (Heidegger, 2006, p. 417-418/GA 29/30, p. 530).

\section{Na metafísica do abismo: finitude da existência, finitude de ser e natureza}

A ontologia fundamental elaborada por Heidegger em ST tem como uma das características centrais o fato de que todo ser é dependente de uma compreensão de ser. A principal consequência dessa característica é que toda possível justificação ontológica será histórica, finita e se pretende não dogmática. Essa condição parte da perspectiva da finitude da existência, pois a compreensão de ser estruturada temporalmente é também finita. É neste sentido que o 
ser-aí humano não é fundamento de sua existência, mas é justamente lançado em um horizonte histórico e colocado no fundamento de sua niilidade, de modo que é preciso assumir esse fundamento negativo mediante a decisão antecipadora, pois é a decisão que leva à verdade originária da existência. Tendo em vista que aquilo que se abre na decisão é sempre único e determinado a cada vez, a finitude impede justamente que haja uma possibilidade que seja fundamentada no ser humano. A existência humana é entendida como um ser-lançado e suspenso no nada.

A finitude da existência é compreendida a partir do conceito de ser para a morte, mais especificamente de como o ser-aí é lançado para o seu fim. A finitude existencial é determinada, sobretudo, pela temporalidade finita, umas vez que é na possibilidade da morte que o futuro originário é desvelado. Sendo assim, com a tese de que a morte é a possibilidade da impossibilidade da existência em geral, como tese interpretativa advogo que Heidegger elabora um conceito de morte existencial ${ }^{10}$ que possui independência do sentido comum e mundano de morte, apresentado mediante o conceito de falecer. A existência do ser-aí somente é vista verdadeiramente através da decisão antecipatória; neste sentido, o falecer, enquanto o modo como ôntica e mundanamente encaramos a possibilidade do nosso fim, depende ontologicamente dessa radicalidade da existência enquanto possibilidade finita de ser.

A partir do radical não estar em casa, a angústia revela de modo genuíno o nada e a niilidade que transpassa a nossa existência finita, mostrando assim a falta de fundamento da existência e a permanente inadequação entre o poder-ser e as possibilidades. Importante ter presente que é somente a partir desse fato que Heidegger diz ser possível existir autenticamente, pois é apenas com o colapso do mundo existencial que podemos advir-a-si mesmos de modo próprio e sair do mundo impessoal. Uma passagem curiosa de Ser e Tempo indica bem o que Heidegger pensa por finitude da existência:

Quando o Dasein, adiantando-se [para a morte], permite que a morte torna-se poderosa nele, então, livre para ela, compreende-se a si mesmo na própria superioridade de poder [Übermacht] de sua liberdade finita (liberdade que somente "é” no fato de haver feito a própria opção), para assumir nessa liberdade finita a impotência [Ohnmacht] de seu estar abandonado a si mesmo e poder ver com clareza as contingências da situação aberta (Heidegger, 2009,p. 397-398/GA 2, p. 508).

Assumir a impotência, nesse caso, é assumir a si mesmo como possibilidade de ser a partir de uma clareza que singulariza o ser-aí humano. O conceito de decisão mostra-se como o instante em que se torna possível assumir a si mesmo livre de qualquer possibilidade fortuita. No entanto, na leitura de Heidegger permanece esse apelo ao nada como aquilo que possibilita uma compreensão autêntica do ser. No caso de ST, o nada ainda diz respeito quase que exclusivamente à existência humana. Em o Que é metafísica?, Heidegger diz o seguinte:

\footnotetext{
“O puro ser e o puro nada são, portanto, o mesmo.” Esta frase de Hegel (Ciência da Lógica, Livro 1 WW III, p. 74) enuncia algo certo. Ser e nada copertencem, mas não porque ambos — vistos a partir da concepção hegeliana do pensamento - coincidem em sua determinação e imediatidade, mas porque o ser mesmo é finito em sua manifestação no ente (Wesen), e somente se manifesta na transcendência do ser-aí suspenso dentro do nada (Heidegger, 1973, p. 13).
}

A conferência Que é metafísica é da mesma época da preleção Conceitos Fundamentais da Metafísica. Nessa conferência, Heidegger também aborda os humores da angústia e do tédio, os problemas da finitude e da metafísica ${ }^{11}$. A questão central é que nessa passagem citada está presente um aceno ao conceito de nada que não concerne mais exclusivamente à existência humana. Neste sentido, um conceito de nada que passa a ser vinculado ao conceito de ser é a

10 Sobre os conceitos de possibilidade e finitude, Cf. Reis (2014, 2016); Cf. Carel (2007). Sobre o conceito de ser para a morte, cf. Thomson (2013).

11 Sobre o conceito de pobreza concernente à existência humana, cf. Reis (2011). 
perspectiva metafísica que guiará Heidegger nas questões da preleção de 1929/30, sobretudo no que diz respeito aos conceitos de mundo como abertura do ente enquanto tal na totalidade e retração. Neste sentido, a finitude é a falta de fundamento não apenas da existência humana, delimitada pela possibilidade da impossibilidade da morte. A finitude de ser aí inserida concerne muito mais a falta de fundamento de todos os sentidos de ser, uma vez que a compreensão do ser dos entes pressupõe a vigência do mundo enquanto um acontecimento fundamental, segundo o qual perpassa e antecede a existência humana. Um dos pontos centrais nessa investigação da recusa do ente na totalidade é de como essa recusa mesma, ancorada no nada, implica na formação de mundo. A finitude da formação de mundo somente será possível através dessa recusa, pois é essa falta essencial que permite à existência humana existir historicamente, equilibrando-se no detalhe do abismo.

Esse conceito de finitude é explicitado pela relação limitada do ser-aí humano com a natureza e com o sentido de ser da vida, tendo como perspectiva de fundo esse movimento de ampliar o conceito de finitude da existência para o conceito de finitude de ser. O fato de o seraí ser banido do ente enquanto tal na totalidade - situação presente na investigação do tédio profundo - mostra de imediato um descentramento no conceito de existência humana. Mas, para além disso, o que está em jogo é o abismo entre existência e natureza. Esse abismo assume um contorno fundamental quando considerados os conceitos determinantes de perturbação, no caso do animal, e na formação de mundo no caso humano. Em uma passagem um pouco longa, Heidegger diz o seguinte:

Ficará claro como o problema do mundo mesmo emerge a partir da tonalidade afetiva fundamental, e, em todo caso, recebe dela de início diretivas totalmente determinadas. Nós nos encontramos diante da tarefa de presentificar para nós agora originariamente os momentos do conceito de mundo que aprendemos a conhecer como caracteres provisórios; e isto à medida que devemos retornar à direção que nos foi aberta pela interpretação do tédio profundo como uma tonalidade afetiva fundamental do ser-aí humano. Mostrar-se-á como essa tonalidade afetiva e tudo o que se encontra nela implicado tem de ser destacado em relação ao que afirmamos como a essência da animalidade em relação à perturbação. Este destaque se tornará para nós tanto mais decisivo, uma vez que justamente a essência da animalidade, a perturbação, aparentemente ganha a mais direta proximidade com o que caracterizamos como um traço do tédio profundo e que chamamos o banimento do ser-aí no interior do ente na totalidade. Com certeza, mostrar-se-á que esta vizinhança mais imediata entre estas duas constituições essenciais é apenas ilusória, que entre elas reside um abismo, um abismo que não pode ser suplantado através de nenhuma mediação qualquer. Mas, então, o fato de estas duas teses se excluírem mutuamente da maneira mais plena possível precisará vir à tona para nós. Quando isto acontecer, a essência do mundo também se apresentará (Heidegger, 2006, p. 323-324/GA 29/30, p. 409).

Essa longa passagem apresenta o ápice da distinção entre os sentidos de ser da existência e da vida. A animalidade foi compreendida como perturbação. A perturbação e o modo como Heidegger a explica assemelham-se bastante a como o ser-aí humano é banido do ente na totalidade pelo tédio profundo ${ }^{12}$. $\mathrm{O}$ animal é privado de compreender o ente enquanto tal mediante a absorção pulsional no interior do espaço de mobilidade de seu círculo de desinibição. A animalidade permanece para o ser humano somente possível de ser compreendida a partir da leitura comparativa entre existência e vida. Por outro lado, a grande diferença aí é que, no caso da existência humana, há uma possibilidade do ser-aí sair do banimento através do instante presente na decisão. A temporalidade originária bane o ser-aí, mas também é possibilitadora, de modo que a finitude de ser, ao englobar a finitude da existência, requer a vigência dos entes para

12 Em O Aberto, Agamben (2013) faz uma análise entre a essência do homem e a essência da animalidade, de um modo distinto e bastante crítico à Heidegger. De acordo com Agamben, o tédio profundo analisado por Heidegger mostraria que a essência do homem se daria a partir da recusa ou “desativação" da privação da animalidade presente na abertura humana. Sobre uma crítica a essa leitura de Agamben, cf. Colony (2007). 
que o ser possa se dar. Por ser possibilitadora, a temporalidade originária possibilita o ser-aí em sua decisão sair da totalidade que se recusa.

Na preleção de 1929/30 Heidegger diz o seguinte:

\begin{abstract}
Apenas no decidir-se do ser-aí para si mesmo, no instante, ele faz uso do que propriamente o possibilita, a saber, do tempo enquanto o instante mesmo. O instante não é nada além da visualização do caráter de decisão, no qual se abre e se mantém aberta na situação plena de um agir. O que retém, portanto, em si o tempo que bane e, em meio à retenção em si, o dá concomitantemente a conhecer como algo passível de produzir liberação; o que o anuncia enquanto possibilidade é algo dele mesmo, o possibilitador que ele mesmo e somente ele mesmo pode ser, o instante. O ser-impelido do ser-aí para o interior do ápice do que propriamente possibilita é o ser-impelido através do tempo que bane para o interior dele mesmo, em sua própria essência: para junto do instante enquanto a possibilidade fundamental da existência própria do ser-aí (Heidegger, 2006, p. 177/GA 29/30, p. 224, grifo do autor).
\end{abstract}

Em Ser e Tempo, o instante da decisão tem a característica de que o poder-ser é fechado e, através disso, o ser-aí pode decidir-se por possibilidades não fortuitas. Aqui, o tempo bane e, através disso e pelo instante temporal, é possível sair do banimento: “o horizonte temporal bane o ser-aí (...), o horizonte temporal, que se torna evidente neste “é entediante para alguém”, só pode ser rompido através do tempo” (Heidegger, 2006, p. 178/GA 29/30, p. 226). Neste sentido é possível ver como ainda mantêm-se algumas das estruturas conceituais entre as duas obras.

É deste modo que o abismo que há entre vida e existência não consiste em ser simplesmente uma separação entre dois entes, uma diferença ôntica. É uma separação abissal que, em última instância, remete à temporalidade originária. Essa separação abissal refere-se também ao fato de o ser-aí humano existir em meio a uma essencial ausência:

O homem é aquele não-poder-permanecer, e, no entanto,não poder-deixar o seu lugar. De maneira projetante, o ser-aí nele o joga constantemente em possibilidades e o retém, com isto, subjugado ao real. Assim jogado, o homem é, em meio à jogada, uma travessia; uma travessia como essência fundamental do acontecimento. O homem é história, ou melhor, a história é o homem. Em meio a travessia, o homem é subtraído, e, por isto, está essencialmente "ausente". Ausente no sentido principial - nunca simplesmente dado, mas ausente, uma vez que ele se perfaz para além de, em meio ao passado essencial e em meio ao por-vir, au-sente e nunca simplesmente, mas, na ausência, um existente (Heidegger, 2006, 418-419/GA 29/30, p. 531, grifo do autor).

Contudo, é justamente esse abismo em meio ao ser-aí humano que perfaz o acontecimento da formação de mundo ser um acontecimento histórico e finito (McNeill, 2006, p. 49). A caracterização comparativa reside na diferença entre o comportamento animal (Benehmen) e o comportamento humano (Verhalten) (Buchanan, 2008, p. 78). No sentido de que ao animal falta, em suma, justamente o “enquanto” (Winkler, 527, 2007), o qual, como caracterização última do momento que designa a irrupção entre ser e ente, indica justamente o acontecimento da formação de mundo. Neste sentido, não há nem mesmo uma abertura a partir da totalidade e, tampouco, desvelamento de ser por parte do animal (McNeill, 1999, p. 238). Consequentemente, ao passo que o ser humano é caracterizado por deixar-ser o ente enquanto tal, o animal é inapto a deixar ser em geral e, por isso mesmo, inapto a deixar ser a si mesmo (McNeill, 1999, p. 242). Desse modo, tampouco a relação do animal com a morte é a mesma que o existente humano possui. Ainda que o animal deva ser compreendido enquanto finitude de ser, a ele é vedado à relação ontológica com a morte e, consequentemente, o animal não toma a si mesmo como um ser finito (McNeill, 1999, p. 224-225). 


\section{Considerações finais}

Ao considerar a retração do ente na totalidade, a vida em específico mostra-se para o ser humano como uma articulação da contingência e da radical finitude que define o ser humano em sua essência (Colony, 2007, p. 14). A natureza mostra-se somente de um modo parcial no compartilhamento intencional com o ser humano. Neste sentido, pelo fato de uma natureza que, em meio à própria retração, mantém o homem cativo, a finitude do ser humano recebe sua mais profunda confirmação, em meio à retração da vida (Winkler, 2007, p. 529). Além disso, a maneira como a animalidade e a natureza vivente têm implicações na abertura de mundo do ser humano é por articular o mundo humano como uma unidade finita, uma unidade que contêm dentro de si modos de ser aos quais resistem à luz do mundo (Colony, 2007, p. 14).

Um aspecto importante e positivo da finitude enquanto condição humana, elaborada na ontologia fundamental, concerne à manutenção do legado histórico. A partir da finitude, se pode compreender autenticamente o legado histórico e manter vigente as compreensões e construções originárias daqueles que existiram. No caso da prelação de 1929/30, o conceito de finitude aí presente permite que uma noção de responsabilidade ecológica ${ }^{13}$ surja a partir da relação incontornável que temos para com a natureza, uma vez que o mundo depende da natureza que não se mostra de modo completo. A despeito do abismo ontológico entre existência e vida ser incontornável quando se parte da leitura de Heidegger.

A abordagem existencial na analítica existencial parece excluir qualquer natureza na existência humana. Por outro lado, um grande êxito de Heidegger foi o de permitir uma abordagem não redutiva concernente ao âmbito do natural. Essa abordagem possui méritos inegáveis, como o fato do pioneirismo em abrir a discussão sobre um conceito de natureza que não seja designado por nenhum outro sentido de ser, seja pelo mecanicismo, seja pelo vitalismo, seja por qualquer positivismo. No entanto, a falta de discussão com as pesquisas de Darwin, seu legado e desdobramentos, certamente podem tornar anacrônicas algumas das considerações heideggerianas, sobretudo as considerações mais ligadas às ciências biológicas. A despeito disso, as considerações histórico-conceituais e a crescente crítica ao modo produtivo do ser humano lidar com o natural, elaboradas por Heidegger, merecem uma boa atenção. Além disso, as questões presentes em Heidegger dizem respeito à possibilidade da própria filosofia. Por outro lado, eventualmente elas recaem em uma defesa do originário dissimuladas por uma linguagem metafísica que dizem o contrário do que está presente em parte de suas análises. É importante partir das considerações de Heidegger, contudo, é também necessário pensar além dele e contra ele, para conseguir situar, de fato, quais são as suas investigações que permanecem potentes. A despeito do antropocentrismo metafísico, que tantos criticaram em Heidegger, ele insere no pensamento do século XX um potente pensamento sobre a finitude e sobre o âmbito da animalidade que foi pioneiro na qualidade com que tratou esses assuntos. Embora em Heidegger o pensamento de uma relação do existente humano com a natureza sempre ser determinada a partir um abismo, é preciso reconhecer que ele buscou compreender a natureza enquanto um âmbito independente e enquanto aquilo que perfaz a abertura de mundo finita do ser humano.

\footnotetext{
${ }^{13}$ Sobre um pensamento ligado à ecologia, cf. Holland (1999).
} 


\section{Referências}

AGAMBEN, Giorgio (2013). “O Aberto”. O Homem e o Animal. Rio de Janeiro: Civilização Brasileira.

AHO, Kevin A. (2009). “Heidegger's Neglect of the Body”. Albany: SUNY Press.

BUCHANAN, Brett (2008). "Onto-ethologies - The animal environments of Uexkull, Heidegger, Merleau-Ponty and Deleuze”. Albany: SUNY Press.

CALARCO, Mathew (2005). “"Another Insistence of Man”: Prolegomena to the Question of the Animal in Derrida's Reading Of Heidegger”. Human Studies 28, pp. 317-334.

CALARCO, Mathew (2008). "Zoographies. The Question of the Animal from Heidegger to Derrida”. New York: Columbia University Press.

CAREL, Havi (2007). "Temporal Finitude and Finitude of Possibility: the Double Meaning of Death in Being and Time”. International Journal of Philosophical Studies, vol. 15, no. 4, pp. 541-556.

COLONY, Tracy (2007). "Before the Abyss: Agamben on Heidegger and the Living". Continental Philosophy Review, vol. 40, no.1, pp. 1-16.

ELDEN, Stuart (2006). “Heidegger's Animals”. Continental Philosophy Review 39, pp. 273291.

HEIDEGGER, Martin. GA 2. Sein und Zeit. Gesamtausgabe 2. Frankfurt am Main: Vittorio Klostermann, 1996.

HEIDEGGER, Martin. GA3. Kant und das Problem der Metaphysik. Frankfurt am Main: Vittorio Klostermann, 1991

HEIDEGGER, Martin. GA 24. Die Grundprobleme der Phänomenologie. 2. Ed. In: Gesamtausgabe 24 (Sommersemester 1927). Frankfurt am Main: Vittorio Klostermann, 1976.

HEIDEGGER, Martin. GA 29/30. Die Grundbegriffe der Metaphysik. Welt - Endlichkeit Eisamkeit. In: Gesamtausgbe 29/30 (Wintersemester 1929/30). Frankfurt am Main: Vittorio Klostermann, 1983.

HEIDEGGER, Martin. GA31. Vom Wesen der menschlichen Freiheit. Einleitung in die Philosophie. Frankfurt am Main: Vittorio Klostermann,1982

HEIDEGGER, Martin. GA 34. Vom Wesen der Wahrheit. Frankfurt am Main: Vittorio Klostermann, 1988.

HEIDEGGER, Martin. (2006). Os Conceitos Fundamentais da Metafísica: Mundo, Finitude e Solidão. Trad.: Marco Antônio Casanova. Rio de Janeiro: Forense Universitária.

HEIDEGGER, Martin. (2012). Os Problemas Fundamentais da Fenomenologia. Trad.: Marco Antônio Casanova. Petrópolis, RJ: Vozes.

HEIDEGGER, Martin. (1973). Que é metafísica? Trad.: Ernildo Stein. Coleção Os Pensadores, São Paulo: Abril Cultural.

HEIDEGGER, Martin. (2009).Ser y tiempo. Madri: Editorial Trotta.

HEIDEGGER, Martin. (1984). The Metaphysical Foundations of Logic. Translated by Michael Heim, Bloomington, Indiana University Press.

HOLLAND, Nancy (1999). "Rethinking ecology in the Western philosophical tradition: Heidegger and/on Aristotle”. Continental Philosophy Review: 32, pp. 409-420.

McNEILL, William (1999). "Life Beyond the Organism: Animal Being in Heidegger's Freiburg Lectures, 1929-30”. In: Steevs, Peter. Animal others. On ethics, ontology, and animal life. New York: State University of New York Press, pp. 197-248.

McNEILL, William (2006). “The Time of Life”. New York: State University of New York Press. REIS, Róbson (2011). "A fragilidade da pobreza”. In: Tourinho \& Bicudo (Orgs.). Fenomenologia: influxos e dissidências. Rio de Janeiro: Booklink, p. 106-127. 
REIS, Róbson (2008). “Notas sobre a origem da negação”. O que nos faz pensar, v. 23, p. 135144.

REIS, Róbson (2014). “Aspectos da Modalidade. A noção de possibilidade na Fenomenologia Hermenêutica”. Rio de Janeiro, RJ: Via Verita.

REIS, Róbson (2016). “Historicality and existential necessity in Martin Heidegger's Being and Time”. Unisinos Journal of Philosophy, vol. 17, no. 1, pp. 2-12.

SILVEIRA, André Luiz Ramalho (2014). "Aspectos de uma interpretação não redutiva da vida em Heidegger: a hermenêutica da natureza e o fenômeno da vida”. Natureza Humana, v.16, pp.138-168.

SILVEIRA, André Luiz Ramalho (2015). “Verdade e logos na interpretação heideggeriana de Aristóteles na preleção de 1929/30”. Peri, v.7, pp.148-165.

THOMSON, Iain (2013). "Death and Demise in Being and Time”. In: Wrathall, Mark A. (ed). The Cambridge Companion to Being and Time. New York: Cambridge University Press, pp 260-290.

TORRES, João Carlos Brum (2010). "Sobre a distinção heideggeriana entre Órgão e Instrumento e a Revolução Biológica Contemporânea”. Revista Filosófica de Coimbra, Vol.38, pp.315-340.

WINKLER, Rafael (2007). "Heidegger and the Question of Man's Poverty in World". International Journal of Philosophical Studies, Volume 15, Issue 4, pp. 521-539. 